ARTICLE HISTORY: Received: September 03, 2021 Accepted: October 27, 2021 Published: November 03, 2021

УДК 316.47 DOL:10.12731/2218-7405

ЭКОНОМИЧЕСКИЕ АСПЕКТЫ РОБОТИЗАЦИИ СОЦИАЛЬНОЙ СФЕРЫ

\author{
Кантарджсян Саркис Левонович \\ Профессор кафедры экономики инноваций ЕГУ, \\ доктор экономических наук \\ 2. Ереван, Республика Армения \\ Погосян Рима Мартиросовна \\ Аспирантка кафедры экономики инноваџий ЕГУ
}

\title{
ECONOMIC ASPECTS OF ROBOTIZATION OF THE SOCIAL SPHERE
}

\author{
Sargis L. Ghantarjyan \\ Professor of the Chair of Innovation Economics in YSU, \\ Doctor of Economic sciences, \\ Yerevan, Republic of Armenia \\ Rima M. Poghosyan \\ PhD student of the Chair of Innovation Economics, YSU
}

\begin{abstract}
Аннотация. Основная цель статьи осветить основные этапы становления нового направления робототехники, известной как социальная, показать подходы к классификации социальных роботов, сферы их применения. Главное отличие социальных роботов от индустриальных заключается в интерактивном взаимодействии с человеком. Приведены описания социальных роботов, используемых в различных странах, перспективы их рынка и отдельные стоимостные характеристики. Отмечается, что армянский социальный робот РОБИН в несколько раз дешевле аналогичных зарубежных прототипов.

Abstract. The main goal of the article is to highlight the basic stages of the formation of a new direction in robotics, known as social, to show approaches in the classification of social robots, their scope of application. The main difference between social robots and industrial robots is their interactive interaction with humans. Descriptions of social robots have made, which used in various countries, their market prospects and individual cost characteristics. It is mentioned that the Armenian social robot ROBIN is a few times cheaper than similar foreign prototypes.

Ключевые слова: робототехника, социальный робот, роботизация

Key words: robotics, social robot, robotization

Введение. Мировой рынок роботов составляет десятки миллиардов долларов, причем растет он в разы быстрее мировой экономики. В соответствии со стандартами Международной федерации робототехники, роботы разделяются на два семейства: созданные для промышленности и для сферы услуг. В литературе, посвященной обзору мирового рынка робототехники, утверждается, что среднегодовые темпы роста этой отрасли составляют около 14\%, и к 2021 году в мире будет выпущено 630 тыс. промышленных роботов.

Начиная с 90-х годов прошлого столетия в робототехнике начало успешно развиваться новое направление социальное роботостроение, связанное с разработкой сервисных роботов, способных удовлетворять потребности различных социальных групп, в частности, работающих в здравоохранении или в сфере обслуживания. Если в 2017 году мировая экономика выросла на 3,7\%, рынок промышленных роботов - на $31 \%$, а рынок сервисных роботов - на $85 \%$ [1].

Обзор литературы по экономике социального роботостроения. На сегодняшний день уже имеется обширная литература по использованию социальных роботов в купе с промышленными роботами, используемыми во многих отраслях промышленности, в частности: космонавтике, обороне, в сельском хозяйстве. Таким образом можно констатировать, что происходит процесс социализации этих отраслей. Об эффективности этого процесса можно судить по многочисленным публикациям результатов целенаправленных исследований, проводимых в Пермском государственном национальном исследовательском университете, а именно на его двух кафедрах - кафедре гуманитарных проблем информатики и кафедре информационных технологий.

Первая публикация по указанной тематике появилась еще в 2013 году, в которой Н.Н Зильберман попыталась как-то связать промышленную и социальную робототехники, утверждая, что «новые» промышленные роботы помимо своих «профессиональных» функций взаимодействуют с человеком, в том
\end{abstract}


числе и на социальном уровне. В этой публикации ею был задан безответный вопрос: «какова роль человека во взаимодействии с такими роботами» [2].

Для нахождения ответа на поставленный вопрос, в последующих статьях автор вместе с коллегами попытались осветить основные подходы к содержанию понятия «социальный робот», выявить определяющие характеристики социального робота в современном контексте социальной робототехники [3]. В частности, с привлечением детей, была сделана попытка использования комплексной методологии эксперимента, основанного на междисциплинарном подходе, включающем взаимодействие робота и ребенка с последующей статистической обработкой полученных результатов [4].

В литературе по социальной робототехнике описаны результаты многочисленных попыток по функциональной классификации социальных роботов. Естественно, что подобную попытку осуществила в начале своих исследований и автор упомянутых выше работ [5]. Тщательно проанализировав имеющиеся публикации по интересующей ее тематике, Н.Н. Зильберман пришла к выводу, что на момент проведения ею исследований «отсутствует единая общепризнанная классификация или единые параметры группировки социальных роботов» и попыталась создать некий прототип возможной классификации социальных роботов. Отметив, что имеется не так уж много примеров разработанных классификаций, автор предложила выделить весьма узкую группу социальных роботов-ассистентов, выполняющих в той или иной степени роль помощника человека в процессе любой его деятельности. Описана работа роботов-барменов, роботов, подающих пищу и сервирующих столы. Во вторую группу автор отнесла роботов, выполняющих узкопрофессиональные функции (роботы-надзиратели в корейских тюрьмах, роботы-учителя опять-таки в корейских детских садах и японских начальных школах, роботы -пожарные).

В особую группу выделены роботы-компаньоны, призванные стать другом человека, стимулировать его эмоции, оказывать терапевтическое воздействие на психику. Отмечается, что для вывода из депрессии пожилых японцев сконструированы роботы-младенцы, имитирующие звуки и движения ребенка, роботы-тюлени, покачивающие головой и ластами, имитирующие голоса детенышей гренландского тюленя.

И, наконец, в третью группу включены социальные роботы, выполняющие в большей степени развлекательные функции. Это роботы артисты, певцы, музыканты.

Следует отметить, что в поисках экономической составляющей социальных роботов авторы настоящей статьи ознакомились и с другими публикациями результатов исследований, проведенных на упомянутых выше кафедрах [6], [7],[8] [9], [10], [11].

К нашему глубокому сожалению, только в одной работе, опубликованной к.э.н., доцентом С.Е. Галумовой в соавторстве с англичанкой Л.Портер в 2019 году удалось найти данные, приближающие авторов к нахождению путей решения поставленной задачи [12]. Упомянутая статья привлекла нас своим заголовком - «Роботизация социальной сферы» и утверждением ее авторов в том, что в ней представлены результаты социологического анализа первых тенденций роботизации социальной сферы и на примере первого в истории случая убийства человека беспилотным такси (2018), сделано предупреждение о возможной угрозе жизни и здоровью людей. Охарактеризована социальная значимость функциональности отдельных образцов сервисных роботов, изобретенных за последние 20 лет и наиболее популярных в мире. Среди них уже упомянутый выше робот Рaro (Япония) в виде детеныша тюленя для пожилых и больных людей — «самый лечебный робот》 по версии Книги рекордов Гиннеса; роботы-андроиды Asimo (Япония), Actroid (Япония), EveR (Южная Корея), Repliee (Япония), Торіо (Вьетнам), Aiko (Канада), HRP (Япония), Ибн Сина (Объединеные Арабские Эмираты), Фрэнк (Швейцария). Все они предназначены для общения и выполнения целого ряда полезных для человека функций; и вышли на уровень массового производства и распространения.

По утверждению авторов цитируемой статьи научные исследования и разработки в области сервисной роботизации начали проводиться довольно давно. Один из подобных исследователей Г. Ху выделяет четыре этапа в развитии робототехники. Современный этап, начавшийся в 2000-е гг., характеризуется созданием так называемых 《сервисных》, то есть обслуживающих человека роботов.

Сервисные роботы обладают следующими характеристиками:

— мобильность,

- программируемость,

— наличие сенсоров,

- механические способности,

- подвижность.

Эти новые возможности позволяют этим роботам быть полезными в различных областях социальной сферы, включая, к примеру, здравоохранение или социальное обслуживание [13].

По утверждению авторов рассматриваемой статьи возникает ряд вопросов, которые относятся к темам будущих научных исследований, а именно:

— может ли сервисный робот полностью заменить человека? 

людей?

- способны ли такие роботы эффективно удовлетворять социальные и эмоциональные потребности

— нужно ли рассматривать заботу роботов о человеке как «пподдельную》?

— как повлияет роботизация на рынок труда и экономику и будут ли низкоквалифицированные сотрудники полностью вытеснены роботами?

— кто должен нести ответственность в случаях нанесения вреда человеку роботом в результате поломки?

Британские ученые уже подсчитали, что 2032г. 250 тыс. сотрудников «общественного сектора» в Великобритании потеряют работу из-за того, что будут заменены на роботов. Сервисные роботы будут выполнять их труд более эффективно и позволят работодателям существенно сэкономить на выплате зарплаты [14].

Результаты уже законченных работ. Исследователь Таканори Сибата, работая в японском научноисследовательском институте интеллектуальных систем «AIST», начиная с 1993г., пытался создать робот Раго в виде детеныша тюленя, который был представлен только в 2001 г. и сразу завоевал популярность. Теперь он используется более чем в 30 странах мира. Его внешний вид вызывает умиление почти у всех людей. Разработчики позиционируют Paro как робота, предназначенного для оказания успокаивающего эффекта и вызова положительных эмоций у пациентов больниц и жителей домов престарелых. У Рано есть несколько сенсоров, которые позволяют ему улавливать различные события, соответствующим образом на них реагируя. Если робота погладить, он виляет «хвостом》, открывая и закрывая глаза. Он реагирует на звуки, отзывается на собственное имя. Рaro способен демонстрировать такие эмоции как удивление, радость или гнев. Голос робота похож на реальный голос детеныша тюленя. Для придания реалистичности он был запрограммирован таким образом, как будто бодрствует днем, а ночью спит. Это «самый лечебный робот》 по версии Книги рекордов Гиннеса. В России его можно приобрести за 590000 руб.

Дальнейшая роботизация социальной сферы осуществлялась за счет более широкого распространения человекоподобных роботов - андроидов.

Еще в 2000 г. корпорацией «Хонда» в Центре фундаментальных технических исследований Вако (Япония) был создан андроид Аsimo. Телосложением он напоминал человека. Усовершенствованная версия робота, созданная в 2014г. имела рост 130см и массу 50кг. Он был способен передвигаться со скоростью до 7км/ч, спускаться с лестницы, распознавать движущиеся объекты и следовать за людьми, распознавать жесты, предметы и поверхности, различать звуки за счет встроенных микрофонов. Этот робот узнавал лица людей и обращался к ним по имени, откликался на собственное имя, поворачивал голову к собеседникам, а также оборачивался на неожиданные и тревожные звуки. Аsimo научили пользоваться Интернетом и локальными сетями. Подключившись к локальной домашней сети, он, к примеру, разговаривал с посетителями через домофон, а потом докладывал хозяину, кто пришел. Получив согласие хозяина принять гостей, Аsimo открывал дверь и провожал посетителя до нужного места [15].

В 2003 г. в Японии была создана первая в мире женщина-андроид (так называемый, «гиноид》 — то есть андроид с женской внешностью). Actroid навсегда изменила представления человечества об андроидах, поскольку выглядела почти как человек. Она была разработана исследовательской группой Хироши Ишигуро из Осакского университета. Функциональность ее, однако, была ограничена, поскольку двигалась только верхняя часть тела. Специалисты называли ее первым в мире гиноидом [16].

Вторым гиноидом в мире стала появившаяся вскоре корейская девушка-робот EveR. Oна похожа на 20летнюю кореянку ростом 1,6м и весом 50кг. Ее разработчики из Южнокорейского института индустриальных технологий предполагали, что EveR сможет служить гидом в музеях, консультантом в универмагах и детским аниматором. Первая версия южнокорейского андроида тоже не могла передвигаться - нижняя часть туловища прикована к креслу. Гиноид мог двигать только верхней половиной тела и руками, демонстрировать четыре выражения лица (радость, гнев, горе и счастье), «понимать» 400 слов, синхронно с их произношением двигать губами, устанавливать контакт глазами с собеседником. Вторая версия EveR научилась стоять [17].

Лаборатория разумной робототехники Осакского университета совместно с отделом аниматроники компании 《Кокоро» (Kokoro Company Ltd) в 2005г. представила еще одну японскую разработку- модель человекоподобного робота Repliee в виде взрослой женщины. Она умела жестикулировать, говорить и даже имитировать эмоции и дыхание. Это стало возможным благодаря функциональной способности двигать глазами, веками, ртом и шеей. Тело Repliee было покрыто силиконом, очень схожим с человеческой кожей. Внутренняя конструкция андроида была сделана из уретана. В 2008г. вышла новая, усовершенствованная версия Repliee c внешностью японской пятилетней девочки. Этот гиноид приковал внимание общественности тем, что был создан для ухода за пожилыми и недееспособными людьми. Функционально, модель предназначалась для оказания помощи в поиске вещей и передвижении, для поддержки беседы и развлечений [18].

Другая модель Repliee была запрограммирована на ведение длительных сложных бесед и интервью. Ее прототипом послужила ведущая новостей Аяко Фудзи (Япония). Глава Лаборатории разумной робототехники Осакского университета Хироши Ишигуро заявил, что через несколько лет роботы будут так похожи на людей, 
что невозможно будет визуально отличить человека от робота-андроида, и когда-нибудь люди будут обманываться, принимая роботов за себе подобных [19].

В 2005 г. вьетнамской компанией TOSY был разработан робот-андроид Торіо для игры в настольный теннис против человека. Он обладает внешностью, напоминающей человеческую, перемещается на двух ногах. Первая публичная демонстрация робота прошла в Токио на выставке International Robot Exhibition в 2007г. Последняя версия робота ростом 1,88м весит около 120кг. Все модели робота используют самообучающуюся систему искусственного интеллекта, позволяющую улучшать свои навыки в процессе игры в теннис.

В 2007г. канадским робототехником-любителем Т. Ли была разработана Aiko — гиноид ростом 151см и весом 30кг с имитацией человеческих чувств: осязания, слуха, речи и зрения [20]. Модель девушки-андроида с искусственным интеллектом стала известна тем, что не только разговаривала, но и читала тексты, распознавала предметы и цвета, реагировала на касания и внешние раздражители и решала математические примеры. Аiko способна оказывать несложную помощь хозяину — например, в зависимости от погоды приносить зонт или кепку и т. п. [21].

Робот-андроид HRP (Humanoid Robotics Project) был создан в Японском национальном институте наук и технологий (AIST). Его гиноидная модификация 2009г. прославилась тем, что предназначена для демонстрации одежды в качестве манекенщицы и выполнения других задач. Рост робота составляет 158см, а вес вместе с батареями 43кг. По замыслу разработчиков, это воплощение среднестатистической японской молодой женщины 19-29 лет. Она умеет разговаривать, распознавать речь, выражать эмоции и неуклюже ходить на полусогнутых ногах [22].

В 2009 г. появился андроид Ибн Сина (Объединенные Арабские Эмираты), названный в честь древнего персидского философа и врача. Он предназначен для путешествий и способен самостоятельно найти свое место в самолете, общаться с людьми на арабском языке. Робот распознает выражение лица говорящего и прибегает к соответствующей ситуации мимике.

В 2011 г. Бертольдом Мейером из Цюрихского университета создан первый в мире биоробот Фрэнк (Франкенштейн). Он назван в честь Виктора Франкенштейна из романа Мэри Шелли 1818 г. Его отличительной особенностью является то, что он оснащен функционирующей системой кровообращения и бьющимся сердцем. В робот встроены 200 процессоров и более 1 млн датчиков. Бионическое тело высотой 183 см состоит из 28 искусственных частей. Фрэнк может ходить и разговаривать, отвечать на вопросы. Управляется он с помощью пульта дистанционного управления либо удаленно через компьютер, подключенный через Bluetooth. Лицо Фрэнка изготовлено из силикона по прототипу внешности его создателя - доктора Мейера. Б. Мейер, будучи социальным психологом, считает, что бионические роботы позволят в будущем создать разработки для замены больных или поврежденных частей тела человека и имплантации искусственных органов [23].

С 2000-х гг. в Западной Европе социальные службы начали использовать первых детей-роботов, имитирующих поведение новорожденных, для работы с молодыми женщинами, планирующими завести ребенка. В последнее десятилетие это направление разработок развивалось все более активно, что позволило достигнуть интересных результатов. В частности, в 2015г. японская компания 《Тоуота〉 разработала и запустила продажи «электронных детей» Kirobo Mini. Цена такого робота составляет 392 доллара. Изначально они позиционировались как роботы для пожилых людей и тех, кому хочется иметь ребенка, но по какой-то причине это невозможно. Но оказалось, что эта разработка не менее популярна и среди других социальных групп - например семей с детьми. Приблизительный возраст такого «ребенка» 一годик. Kirobo Mini помещаются на ладони человека, могут немного ходить, причем такое недостаточное умение передвигаться спроектировано инженерами специально для того, чтобы вызывать у человека нежные чувства и стимулировать появление эмоциональной связи с роботом. Этот робот способен реагировать на жесты, показывать что-то самостоятельно, умеет определять эмоции владельца и реагирует соответствующим образом, пытается разговаривать детским голосом (уровень навыка речи можно изменять в настройках). В комплекте с роботом поставляется и специальная док-станция, похожая на детское автокресло и подходящая по размеру к держателю стаканов в автомобиле.

Любопытно, что «Tоуоta》 также будет собирать данные об особенностях вождения автомобиля владельцем робота, если тот даст на это согласие и будет брать Kirobo Mini с собой в дорогу. Это будут обезличенные данные, на основе анализа которых специалисты смогут улучшать конструкцию автомобилей [24].

В 2016 г. появился первый «социальный робот для семьи» Jibo, разработанный специалистами Массачусетского технологического института (США) под руководством специалиста по робототехнике, доктора наук Синтии Брейзеаль. Цена этого робота составляет 499 долларов. Он пополнил ряд роботов, созданных специально для общения с человеком. Он оснащен большим количеством сенсоров и современным программным обеспечением, что позволят устройству узнавать всех членов семьи (распознавать лица). Разработчики утверждают, что Јibo с каждым человеком устанавливает «эмоциональную связь» и общается по-разному. Он может помогать в работе, выполняя роль ассистента, напоминающего о запланированных в 
календаре мероприятиях или зачитывающего пришедшие сообщения. Jibo может помогать, допустим, на кухне во время приготовления пищи, находя по просьбе хозяина и зачитывая нужные рецепты в Интернете [25].

Описав возможности российского сервисного робота Promobot, разработанного пермской компанией ООО «МИП Интеллект», авторы разбираемой статьи особое внимание уделили перспективам его внедрения в социальную сферу. Робот предназначался для взаимодействия с людьми и развлечений. Именно поэтому его рекомендовали использовать в местах повышенного скопления людей, в которых он, передвигаясь автономно и избегая столкновений, помогал людям ориентироваться и общаться. Он отвечал на любые вопросы, транслировал промо-материалы на своем дисплее и запоминал каждого, с кем он общался. Робот шутит и делает комплименты, что не может не поднимать настроение. Он способен автоматически подъезжать к зарядному устройству после 8 часов работы. Общение поддерживается на 7 языках на основе обширной лингвистической базы и интеграции с поисковыми системами. Промобот может интегрироваться с внешними устройствами и сервисами.

В дальнейшем для продвижения этой быстро завоевавшей огромную популярность во всем мире разработки компания Promobot стала резидентом фонда Сколково и крупнейшим производителем автономных сервисных роботов на территории России, Северной и Восточной Европы. Сегодня несколько сотен таких роботов работают практически на каждом континенте, более чем в двенадцати странах. В 2018г., к примеру, было заключено пять новых контрактов с Бразилией, Канадой, Румынией, Кувейтом и Германией на 2 млн долларов, что составляет половину российского экспорта в данной отрасли. Компания в этих странах получила статус официального дилера и будет внедрять роботы Promobot V.4 в бизнес-центры, торговые центры, банки, музеи и другие места повышенного скопления людей.

По оценкам экспертов, благодаря компании Promobot, ни в одной стране мира, кроме России, нет такого большого количества сервисных андроидных роботов на службе у различных компаний. Они трудятся по всей России от Краснодара до Якутска в качестве администраторов, промоутеров, хостес, музейных гидов, в таких компаниях как НПФ «Сбербанка», МФЦ, «Билайн》, Музей современной истории России, «Московский метрополитен〉 [26], 《Пермэнергосбыт》 [27], различных торговых центрах, и способны повысить качество сервиса и лояльность клиентов. Например, с 2015г. в Якутске в МФЦ Промобот выступает в качестве администратора зала и рассказывает посетителям про услуги компании. У него можно проконсультироваться практически по любому вопросу, например: «Какие документы нужны для загранпаспорта? 》, или «Где можно сделать копию?». По оценкам специалистов МФЦ, робот разгрузил администраторов зала, многие посетители теперь с вопросами обращаются к нему. Чтобы посетители привыкли к такой процедуре, потребовалось три месяца [28].

Разработчики Промобота предлагают сегодня заменять на роботов сотрудников различных организаций. К достоинствам такого «работника» они относят то, что:

— робот всегда с радостью и улыбкой проконсультирует по любому вопросу, без усталости и перерывов;

- обладая уникальным внешним видом, робот способен расположить к себе любого клиента;

- роботы-сотрудники - это то, что выделит любую компанию среди конкурентов;

- робота, в отличие от человека, возможно переобучить в кратчайшие сроки;

— робот снизит риски, связанные с человеческим фактором.

Компания Promobot предлагает использовать свою разработку в следующих областях:

1. Промобот для образования (как образовательный стенд, на основе которого обучающиеся получат актуальные технические компетенции).

2. Промобот-консультант (консультации по любым вопросам, сканирование паспорта и оформление договора, интеграция с системой электронной очереди и выдача талонов, совершение денежных операций с помощью встроенного банковского терминала, произнесение промо-речевок).

3. Промобот-консьерж (распознавание лиц, идентификация посетителя, сканирование паспорта, выдача карт-пропусков, интеграция с системой учета постояльцев или пропускной системой, выдача пропусков или открытие турникета, оплата коммунальных услуг через встроенный в робота банковский терминал, общение, информирование о новостях управляющей компании, территории проживания, сроках оплаты и задолженностях, сопровождение посетителя до лифта или любого другого пункта).

4. Промобот для ритейла (информирование покупателей об ассортименте и акциях, идентификация посетителя, промо-режим либо режим взаимодействия, денежные операции через банковский терминал, печать чеков и купонов, интеграция с системой учета клиентов и системой учета товаров, считывание штрих-кодов, изготовление и выдача карт, сопровождение покупателя до необходимого стеллажа).

5. Робот-сотрудник банка (распознавание лиц посетителей, приветствие, выдача талона электронной очереди, информирование о продуктах банка, обратная связь, заключение договора на услуги банка с клиентом).

6. Робот-промоутер (качественное донесение любой информации и консультирование без волнения, усталости и дефектов речи). 
7. Робот-сотрудник бизнес-центра (помощь в навигации по помещению, демонстрация фото и видеоматериалов, информирование об инфраструктуре центра, услугах и продуктах, идентификация посетителей, общение).

8. Робот-администратор (информирование и консультирование посетителей, идентификация посетителей, общение).

9. Робот-экскурсовод (проведение экскурсий для посетителей, информирование об экспонатах, ответы на вопросы и трансляция фото- и видеоматериалов на встроенном мониторе).

Первый армянский сервисный робот. Хотелось-бы закончить этот обзор приятной новостью, опубликованной в армянской прессе [29]. В Ереване функционирует стартап Ехррег, изготовивший модель робота, распознавающий эмоции. По словам руководителя компании К.Хачикяна новому «детищу присвоено имя РОБИН». Согласно информации, опубликованной в журнале ТIMЕ в список ста лучших инноваций 2011года попало и изобретение Карена Хачикяна. Это первый армянский робот-компаньон с искусственным интеллектом, созданный для лежащих в больницах детей - чтобы им не было так тревожно и одиноко. Далее в публикации говорится о том, что Робин выглядит как персонаж студии Рiхаг - с большими глазами и веселым характером. Он способен распознавать эмоции ребенка и реагировать на них, развлекать забавными историями и анекдотами, а также просто и понятно рассказывать о медицинских процедурах. Сейчас робот используется в 12 учреждениях по всему миру и в ближайший год должен появиться еще и в США. Робин уже доказал свою эффективность: ТІМЕ опубликовал трогательную историю о восьмилетней девочке, лежавшей в одной из клиник Армении с пневмонией. Пациентка отказывалась есть на протяжении двух дней, и тогда сотрудники больницы решили воспользоваться помощью Робина. После 20-минутной беседы робот попрощался, пообещав вернуться, если ребенок согласится поесть. И тогда девочка принялась за еду. Впрочем, это далеко не единственный случай. Согласно исследованию, проведенному еще в прошлом году среди ста детей, находившихся в клиниках Армении, после общения с роботом уровень их стресса снизился на 34\%. По словам Карена Хачикяна, дети, которые долгое время пребывают в больницах, напуганы, склонны к апатии и потере аппетита, ведь лечение зачастую бывает болезненным. Однако после общения с Робином пациенты становились более бодрыми и были заинтересованы в новой встрече. Кроме того, Робин может разговаривать с клиентами банков, магазинов и других точек обслуживания. Он умеет передвигаться и понимать речь, различать эмоции людей. Робот оснащен 3d-камерами, инфракрасным лазером и сложной системой распознавания лиц. Но самое главное - в три-четыре раза дешевле аналогичных роботов, выпускаемых за-рубежом

Заключение. В заключении этой статьи отметим, что Международная федерация робототехники (IFR), проводящая и публикующая подобные исследования [30], утверждает, что роботы, предназначенные для социального использования, завоевывают все большую популярность и способствуют автономизации (то есть процессу формирования независимости, самостоятельности) личности. Это приводит к революционным изменениям в социальной сфере. Создаются принципиально новые возможности для работы, творчества, получения образования и развлечения в домашних условиях. Благодаря процессу роботизации социальной сферы, может повыситься информационная культура общества и измениться общественное сознание. https://trends.rbc.ru/trends/innovation/5d651aa49a7947477f13a2a4 (27.11.2021)

2. Зильберман Н.Н. Социальные роботы - помощники на производстве // Гуманитарная информатика. 2013 г. вып. 7

3. Зильберман Н.Н., СтефанцоваМ.А. Социальный робот: подходы к определению понятия // Современные методы исследования социальных проблем № 11(67) 2016

4. Зильберман Н.Н., ЧекуноваА.В., Гладкий Д.А., Куликов И.А. Стереотипные Представления детей о статусно-ролевых характеристиках социального робота (экспериментальное исследование) // Современные методы исследования социальных проблем N18, 2015

5. Зильберман Н.Н. Функциональная классификация социальных роботов // Гуманитарная информатика. 2014 г. вып.8

6. Зильберман Н.Н., Слободская А.В. Восприятие различных типов культурного интерфейса социального робота // Universum: общественные науки: электрон. научн. журн. 2014. № 10-11 (11)

7. Зильберман Н.Н. Обзор исследований восприятия социального робота в статусе выше человека // Гуманитарная информатика. 2017 № 13. с.30-38

8. Е.С. Шандаров, А.Н. Зимина, П.С. Ермакова Анализ поведения робота-ассистента в рамках разработки сценариев взаимодействия робот-ребенок // Гуманитарная информатика. 2014. Вып. 8 с.51-62

9. Зильберман Н.H. Hello Barbie-интерактивная кукла или социальный робот? // Гуманитарная информатика. 2017 №12 с 32-39 
10. .Зильберман Н.Н, Пархоменко А.А. Представление о возможной роли робота в социальном статусе выше человека (на примере дискурса игры в дебаты) // Гуманитарная информатика. 2017 № 12 с.40-49

11. Зильберман Н.Н, Куликов И.А.,Слободская А.В.,Шатыло Р.В., Калиневич Н.А. Методология проведения исследования восприятия культурного интерфейса социального робота // Гуманитарная информатика. 2014. № 8. С. 93-98

12. Гасумова С.Е., Портер Л. Роботизация социальной сферы // Социология науки и технологий. 2019. № 1. C. 79-94.

13. Porter L. Can Technology Enhance Heath and Social care? An overview of Robotics and Smart Technology (Powerpoint Presentation). University of Worcester, 2018.

14. Robots could replace 250,000 UK public sector workers // The Guardian. 2017. 6 Feb. URL:

https://www.theguardian.com/technology/2017/feb/06/robots-could-replace-250000-uk-public-sector-workers. Accessed: 29.11.2021.

15. The Honda Worldwide ASIMO Site: ASIMO news, development, and technological details. URL: https://world.honda.com/ASIMO/. Accessed: 29.11.2021

16. Actroid-DER series // Kokoro. Available from: https://www.kokoro-dreams.co.jp/english/rt_tokutyu/actroid/. Accessed: 29.11.2021.

17. Корея обнародовала девушку-андроида // Membrana. 2006. 10 мая [Электронный ресурс]. http://www.membrana.ru/particle/9965. Дата обращения: 29.11.2021

18. Repliee - линейка женских роботов-андроидов // Новости технологий. 2008. 12 окт.[Электронный pecypc]. http://techvesti.ru/node/491. Дата обращения: 29.11.2021.

19. Repliee Q2 - самый 《человечный》 андроид // Ferra.ru. 2007. 24 дек. [Электронный ресурс]. https://www.ferra.ru/ru/techlife/news/2007/12/24/repliee-q2-samyy-chelovechnyy-android/.Дата обращения: 29.11.2021.

20. Project Aiko [Online]. http://projectaiko.com/. Accessed: 29.11.2021.

21. Aiko - женский робот-андроид с искусственным интеллектом // Новости технологий. 2008. 21 авг. [Электронный ресурс]. http://techvesti.ru/node/343.Дата обращения: 29.11.2021.

22. Новый робот-женщина усердно уподобляется человеку // Membrana. 2009.16 марта [Элетронный pecypc]. http://www.rsci.ru/science_news/152252.php. Дата обращения: 29.11.2021.

23. Woollaston $V$. Meet Frank, the world's first walking, talking bionic man complete with artificial limbs and a beating heart // Daily Mail. 2013. 18 Oct. [Online]. https://www.dailymail.co.uk/sciencetech/article-2465853/MeetFrank-worlds-walking-talking-bionic-man-complete-artificial-limbs-beating-HEART.html. Accessed: 29.11.2021.

24. 《Тоyota》 разработала робота-ребенка для пожилых японцев // Habr. 2016. 3 октября [Электронный pecypc]. https://habr.com/post/372727/. Дата обращения: 29.11.2021.

25. Jibo [Online]. https://www.jibo.com/. Accessed: 29.11.2021

26. Промобот продал роботов в пять новых стран // Promobot. 2018. 16 авг. [Электронный ресурс]. https://promo-bot.ru/blog/trk-perm-mfc-yakutiya/. Дата обращения: 29.11.2021.

27. 《Пермэнергосбыт》 принял на работу робота-консультанта // Пермэнергосбыт [Электронный ресурс]. 2018. 24 окт. https://permenergosbyt.ru/press/2018-10-24_permenergosbyt-prinyal-na-rabotu-robota-konsultanta. Дата обращения: 29.11 .2021

28. Сервисные роботы на службе торговых центров Перми и МФЦ Якутии // Promobot 2015. 9 фев. [Электронный pecypc]. https://promo-bot.ru/blog/trk-perm-mfc-yakutiya/. Дата обращения: 29.11.2021

29. https://www.armmuseum.ru/news-blog/robin-the-robot-the-best-inventions-of-2021. Дата обращения: 29.11.2021

30. Why service robots are booming worldwide // IFR Press Releasesю Available at: https://ifr.org/news/whyservice-robots-are-booming-worldwide. Accessed: 29.11.2021.

1. Makarenko G. Chto proiskhodit na mirovom rynke robototekhniki https://trends.rbc.ru/trends/innovation/5d651aa49a7947477f13a2a4 (27.11.2021)

2. Zilberman N.N. Social robots - production assistants // Gumanitarnaya informatika. 2013. Issue7

3. Zilberman N.N., Stefantsova M.A. Social robot: approaches to the definition of the concept // Sovremennyye metody issledovaniya sotsial'nykh problem № 11(67) 2016

4. Zilberman N.N., Chekunova A.V., Gladkiy D.A., Kulikov I.A. Stereotypical Ideas of Children about the StatusRole Characteristics of a Social Robot (an Experimental Study) // Sovremennyye metody issledovaniya sotsial'nykh problem N18, 2015

5. Zilberman N.N. Functional classification of social robots // Gumanitarnaya informatika. 2014. Issue8

6. Zilberman N.N., Slobodskaya A.V. Perception of different types of cultural interface of a social robot // Universum: obshchestvennyye nauki: elektron. nauchn. zhurn. 2014. № 10-11 (11) 
7. Zilberman N.N. Review of studies on the perception of a social robot in a status higher than a human // Gumanitarnaya informatika. 2017 № 13. c.30-38

8. E.S. Shandarov, A.N. Zimin, P.S. Ermakova Analysis of the behavior of a robot-assistant in the development of scenarios for interaction between a robot-child // Gumanitarnaya informatika. 2014. Issue 8 pp.51-62

9. Zilberman N.N. Hello Barbie Interactive Doll or Social Robot? // Gumanitarnaya informatika. 2017 №12 c 3239

10. . Zilberman N.N., Parkhomenko A.A. The idea of the possible role of a robot in a social status higher than a person (on the example of the discourse of a game of debate) // Gumanitarnaya informatika. 2017 № 12 c.40-49

11. Zilberman N.N., Kulikov I.A., Slobodskaya A.V., Shatylo R.V., Kalinevich N.A. Methodology for conducting research on the perception of the cultural interface of a social robot // Gumanitarnaya informatika. 2014. № 8. C. 93-98

12. Gasumova S.E., Porter L. Robotization of the social sphere // Sotsiologiya nauki i tekhnologiy. 2019. № 1. PP. 79-94.

13. Porter L. Can Technology Enhance Heath and Social care? An overview of Robotics and Smart Technology (Powerpoint Presentation). University of Worcester, 2018.

14. Robots could replace 250,000 UK public sector workers // The Guardian. 2017. 6 Feb. URL:

https://www.theguardian.com/technology/2017/feb/06/robots-could-replace-250000-uk-public-sector-workers.

Accessed: 29.11.2021.

15. The Honda Worldwide ASIMO Site: ASIMO news, development, and technological details. URL: https://world.honda.com/ASIMO/. Accessed: 29.11.2021

16. Actroid-DER series // Kokoro. Available from: https://www.kokoro-dreams.co.jp/english/rt_tokutyu/actroid/. Accessed: 29.11.2021.

17. 17. Korea unveiled an android girl // Membrana. 2006. May 10 [Electronic resource]. http://www.membrana.ru/particle/9965. Date of access: 11/29/2021

18. 18. Repliee - a line of female android robots // Technology News. 2008. October 12 [Electronic resource]. http://techvesti.ru/node/491. Date of access: 11/29/2021.

19. Repliee Q2 - the most 《human》 android // Ferra.ru. 2007. 24 dec. [Electronic resource]. https://www.ferra.ru/ru/techlife/news/2007/12/24/repliee-q2-samyy-chelovechnyy-android/. Date of access: 29.11.2021.

20. Project Aiko [Online]. http://projectaiko.com/. Accessed: 29.11.2021.

21. Aiko - a female android robot with artificial intelligence // Novosti tekhnologiy. 2008.21 aug. [Electronic resource]. http://techvesti.ru/node/343. Accessed: 29.11.2021.

22. New robot woman assiduously assimilates to human // Membrana. 2009.16 March [Electronic resource]. http://www.rsci.ru/science_news/152252.php. Accessed: 29.11.2021.

23. Woollaston $V$. Meet Frank, the world's first walking, talking bionic man complete with artificial limbs and a beating heart // Daily Mail. 2013. 18 Oct. [Online]. https://www.dailymail.co.uk/sciencetech/article-2465853/MeetFrank-worlds-walking-talking-bionic-man-complete-artificial-limbs-beating-HEART.html. Accessed: 29.11.2021.

24. 《Toyota》 has developed a robot child for elderly Japanese // Habr. 2016.3 October [Electronic resource]. https://habr.com/post/372727/. Accessed: 29.11.2021.

25. Jibo [Online]. https://www.jibo.com/. Accessed: 29.11.2021

26. The promobot sold robots to five new countries // Promobot. 2018.16 Aug. [Electronic resource]. https://promo-bot.ru/blog/trk-perm-mfc-yakutiya/. Accessed: 29.11.2021.

27. Permenergosbyt hired a robot consultant // Permenergosbyt [Electronic resource]. 2018.24 oct. https://permenergosbyt.ru/press/2018-10-24_permenergosbyt-prinyal-na-rabotu-robota-konsultanta. Accessed: 29.11.2021

28. Service robots in the service of shopping centers in Perm and MFC Yakutia // Promobot 2015. 9 feb. [Electronic resource]. https://promo-bot.ru/blog/trk-perm-mfc-yakutiya/. Accessed: 29.11.2021

29. https://www.armmuseum.ru/news-blog/robin-the-robot-the-best-inventions-of-2021. Дата обращения: 29.11.2021

30. Why service robots are booming worldwide // IFR Press Releasesю Available at: https://ifr.org/news/whyservice-robots-are-booming-worldwide. Accessed: 29.11.2021. 